\title{
Incompletely Condensed Silsesquioxanes: Formation and Reactivity
}

\author{
Dong Woo LeE and Yusuke KAWAKAMI ${ }^{\dagger}$ \\ Graduate School of Materials Science, Japan Advanced Institute of Science and Technology, \\ Asahidai 1-1, Nomi 923-1292, Japan
}

(Received November 22, 2006; Accepted December 10, 2006; Published January 24, 2007)

\begin{abstract}
Hydrolysis reaction products from aryltrialkoxysilanes were studied in various solvents with alkali and alkaline earth metal hydroxides. Definite products could be isolated when sodium hydroxide was used. Reaction of trimethoxy- or triethoxyphenylsilane with equimolar amounts of sodium hydroxide to the silicon compound in refluxing water- $i$-propanol gave cyclic sym-cis tetraphenylsilsesquioxanetetraol tetrasodium salt as the principal product. When a little excess of sodium hydroxide than half molar amounts to the silicon compound was used, only small amounts of the cyclic tetramer was noticed among the initial products together with cubic octaphenylsilsesquioxane, evidenced by mass spectroscopy. Heptaphenylsilsesquioxanetriol trisodium salt was formed after refluxing for $4 \mathrm{~h}$ and following stirring for $15 \mathrm{~h}$ at room temperature. With longer reaction time, a double-decker octaphenyl silsesquioxanetetraol tetrasodium salt was obtained in high yield with the consumption of heptaphenylsilsesquioxanetriol. While the silanols of double-decker octaphenyl silsesquioxanetetraol were thermally stable against condensation up to $230{ }^{\circ} \mathrm{C}$, the sodium salt smoothly reacted with dimethyldichlorosilane to give completely condensed cage, 7,7,17,17-tetramethyl-1,3,5,9,11,13,15,19-octaphenylhexacyclo[9.13.1 $\left.1^{1,9} \cdot 1^{3,15} \cdot 1^{5,13} \cdot 1^{11,19}\right]$ decasiloxane.

[doi:10.1295/polymj.PJ2006169]

KEY WORDS Phenyltri(m)ethoxysilane / sym-cis Cyclic Tetrasilsesquioxanetetraol / Heptaphenylsilsesquioxanetriol / Double-Decker Octaphenylsilsesquioxanetetraol / POSS / Single-Crystal X-Ray Diffraction /
\end{abstract}

The development of new materials with specially designed chemical, mechanical or physical properties becomes increasingly important in order to meet the various practical requirements in many fields of application. ${ }^{1-3}$

Over the past decade, completely and incompletely condensed polyhedral oligomeric silsesquioxanes (POSS), obtained by hydrolysis and condensation of trifunctional alkyl- or arylsilane, have attracted considerable interest due to their unique properties such as high thermal stability to enhance the glass transition temperature $\left(T_{\mathrm{g}}\right),{ }^{4-7}$ low dielectric constant, and oxidative resistance of POSS-based polymeric materials.

$\mathrm{Scott}^{8}$ initially discovered completely condensed methyl-substituted oligomeric silsesquioxanes in 1946. Barry ${ }^{9}$ first showed the cubic or hexagonal prismatic shape of the completely condensed molecules. Brown and Vogt made major contributions to the synthesis of phenyl-substituted silsesquioxane cages. ${ }^{10}$ Feher synthesized three new incompletely condensed POSS, namely trisilanols $\left[\left(c-\mathrm{C}_{5} \mathrm{H}_{9}\right)_{7} \mathrm{Si}_{7} \mathrm{O}_{9}(\mathrm{OH})_{3}\right.$, $\left[\left(c-\mathrm{C}_{7} \mathrm{H}_{13}\right)_{7} \mathrm{Si}_{7} \mathrm{O}_{9}(\mathrm{OH})_{3}\right]$, and tetrasilanol $\left[\left(c-\mathrm{C}_{7} \mathrm{H}_{13}\right)_{6^{-}}\right.$ $\left.\mathrm{Si}_{6} \mathrm{O}_{7}(\mathrm{OH})_{4}\right]$, in $29 \%, 26 \%$ and $7 \%$ yield, respectively. ${ }^{11}$

It has been well-recognized that structure of the products, such as cubic and other cages of completely or incompletely condensed form, branched polymers and double-chain polymers, depends on the reaction conditions such as molar ratio of reactants, catalyst, solvent, temperature, concentration, and organic group on silicon atom, which seem to have been generated from multi-step processes via many different intermediates. $^{12}$

We reported the tendency of loop formation, ${ }^{13}$ and the effect of substitutents on aryl group in the formation of completely-condensed octaarylsilsesquioxane as the benzene insoluble fraction from (substituted phenyl)trimethoxysilane. The firstly formed linear or low branched structures containing 6-9 silicon atoms by intermolecular condensation seem to further condense to form loop and cage structures. ${ }^{14}$

In this report, we deal with the products under strongly basic condition. Special interest was given to the formation of the sym-cis cyclic tetramer, tetraphenylsilsesquioxanetetraol (T4OH), heptaphenylsilsesquioxanetriol $(\mathrm{T} 7 \mathrm{OH})$ and double-decker octaphenylsilsesquioxanetetraol (DDT8OH) structures. Since the T7 and DDT8 are very interesting starting materials for the synthesis of siloxane polymers with unique structure, general synthetic conditions, unambiguous determination of the structure, and stability and reactivity were studied in detail.

${ }^{\dagger}$ To whom correspondence should be addressed (Tel: +81-761-51-1630, Fax: +81-761-51-1635, E-mail: kawakami@jaist.ac.jp). 


\section{EXPERIMENTAL}

\section{General}

Fourier transform-infrared (FT-IR) spectra were obtained as $\mathrm{KBr}$ disc on a JASCO VALOR-III (resolution of $4 \mathrm{~cm}^{-1}, 400-4000 \mathrm{~cm}^{-1}$ ) with TGS detector at room temperature. High resolution NMR spectra $\left(500 \mathrm{MHz}{ }^{1} \mathrm{H}, \quad \delta_{\mathrm{CHCl}_{3}}=7.26 \mathrm{ppm} ; \delta\right.$ acetone- $d_{5}=$ $2.05 \mathrm{ppm}, 99 \mathrm{MHz}{ }^{29} \mathrm{Si}, \delta_{\mathrm{TMS}}=0.00 \mathrm{ppm}$ ) were obtained on a Varian NMR spectrometer model Unity INOVA. Spin-lattice relaxation times $\left(T_{1}\right)$ were obtained at spinning rate of $4 \mathrm{kHz}$ with solid state ${ }^{29} \mathrm{Si}$ NMR $(79 \mathrm{MHz})$ of Varian NMR INOVA 400 using an inversion-recovery pulse sequence. GC-MS spectra were measured by a SHIMADZU GC-17A and QP-5000 (quadropole). For MALDI-TOF MS (Shimadzu-Kratos Kompact MALDI III) analysis, the matrix 2,5-dihydroxybenzoic acid 98\% (DHBA) was dissolved in THF $(50 \mathrm{mg} / \mathrm{mL})$, and mixed with the sample solution $(0.1 \mathrm{mg} / \mathrm{mL}$ in THF) in $1: 1 \mathrm{v} / \mathrm{v}$ ratio. The samples were dried in air at least for 30 min, and the measurement was done in linear mode, with UV laser $(337 \mathrm{~nm})$. The spectra were calibrated by the use of bradykinin. All data were collected by laser power more than $100 \mathrm{~W}$, above the threshold in positive ion mode with accumulation of 50-100 shots. Size exclusion chromatography (SEC) was performed on a JASCO high speed liquid chromatograph, model Gulliver 900 with the combination of Shodex KF-801 (exclusion limit: polystyrene, $1.5 \times 10^{3}$ dalton) and KF-802 (exclusion limit: polystyrene, $5.0 \times$ $10^{3}$ dalton) using THF $(1 \mathrm{~mL} / \mathrm{min})$ as an eluent. Thermogravimetric analyses (TGA) were performed on a Seiko SSC $/ 5200 \mathrm{H}$ instrument at a heating rate of $10^{\circ} \mathrm{C} / \mathrm{min}$ under nitrogen atmosphere $(50 \mathrm{~mL} / \mathrm{min})$. In single crystal $\mathrm{X}$-ray analysis, all measurements were made on a Rigaku RAXIS imaging plate area detector with graphite monochromatic Mo-K $\alpha$ radiation $(\lambda=0.71075 \AA)$ at $50 \mathrm{kV}$ and $40 \mathrm{~mA}$. The structure was solved by direct method (SIR92) and expanded using Fourier techniques (DIRDIF99) for all crystal.

\section{Materials}

Phenyltrimethoxysilane (>99.0\%), phenyltriethoxysilane (>99.0\%), trimethylchlorosilane (>99.0\%) and dimethyldichlorosilane ( $>99.0 \%$ ) were purchased from Shin-Etsu Chemical and used without further purification. Phenyltri(2-methoxyethoxy)silane was prepared according to the method by Burkhards ${ }^{15}$ and purified by distillation [bp $142^{\circ} \mathrm{C} / 0.2$ Torr]. Acetic acid (>99.5\%) was purchased from Wako Pure Chemical. Tetrahydrofuran (THF) and other solvents were purchased from Wako Pure Chemical and distilled from calcium hydride. (Substituted-phenyl)trimethoxysil- anes used in this study are (4-methylphenyl)trimethoxysilane $\left[\mathrm{bp}=59^{\circ} \mathrm{C} / 0.41\right.$ Torr $]$, (4-methoxyphenyl)trimethoxy silane $\left[\mathrm{bp}=80-81^{\circ} \mathrm{C} / 0.30\right.$ Torr $]$, and (4-dimethylaminophenyl)trimethoxysilane [bp $=127$ $131^{\circ} \mathrm{C} / 0.53$ Torr].

The reagents were prepared by typical Grignard reaction. For example, (4-methylphenyl)trimethoxysilane was prepared from $30 \mathrm{mmol}$ of 4-bromotoluene and $33 \mathrm{mmol}$ of dried magnesium turning in $100 \mathrm{~mL}$ 2-mouth round bottom flask with $24 \mathrm{~mL}$ dry THF. After the reaction occurred, the reaction system was further kept under stirring for $2 \mathrm{~h}$. Grignard reagent obtained was transferred to another $100 \mathrm{~mL}$ flask with a dropping funnel, and added dropwise into $45 \mathrm{mmol}$ tetramethoxysilane in $24 \mathrm{~mL}$ dry THF in an ice bath. The product (4-methylphenyl)trimethoxysilane was directly distilled from the reaction mixture. The purity was checked by GC-MS. All compounds gave reasonable NMR chemical shifts. (4-methylphenyl) trimethoxysilane, $\delta$ : 7.57-7.54 (d, 2H), 7.23-7.21 (d, 2H), 3.62 (s, 9H), 2.37 (s, 3H); (4-methoxyphenyl)trimethoxysilane, $\delta$ : 7.57-7.60 (d, 2H), 6.92-6.95 (d, 2H), 3.82 (s, 3H), 3.61 (s, 9H); (4-dimethylaminophenyl)trimethoxysilane, $\delta: 7.53-7.50(\mathrm{~d}, 2 \mathrm{H}), 6.75-6.72(\mathrm{~d}$, $2 \mathrm{H}), 3.60$ (s, 9H), 2.98 (s, 6H).

\section{Hydrolysis of Trialkoxyphenylsilane}

Reactions were carried out basically by modifying the previous report. ${ }^{16}$ Trialkoxyarylsilane $(0.24 \mathrm{~mol})$ was added dropwise to a solution of alkali metal hydroxide (molar ratio of Si:alkali metal $=1: 1$ or $2: 1 \mathrm{~mol} / \mathrm{mol})$, solvent $(240 \mathrm{~mL})$ and deionized water $(0.24-0.28 \mathrm{~mol})$ at a room temperature in about 15 min. The reaction mixture was heated to reflux for $4 \mathrm{~h}$ under nitrogen. The solution was cooled to ambient temperature to produce precipitates. After filtration, the precipitate was dried at $70^{\circ} \mathrm{C}$ for $5 \mathrm{~h}$ in a vacuum oven.

\section{Silylation with Trimethylchlorosilane}

Trimethylchlorosilane ( $42.4 \mathrm{mmol}$ ) was added dropwise to the alkali salt precursor (1.3 or $2.4 \mathrm{~g}$ ) obtained above by molar ratio ( $\mathrm{Si}: \mathrm{Na}=1: 1$ or $2: 1)$ and triethylamine $(35.6 \mathrm{mmol})$ in THF $(20 \mathrm{~g})$ for one minute while stirring by a magnetic stirrer under nitrogen. Stirring was further continued at room temperature for $3 \mathrm{~h}$. Deionized water $(10 \mathrm{~g})$ was added to dissolve produced sodium chloride and to hydrolyze unreacted trimethylchlorosilane. The organic layer was separated by means of a separating funnel.

In the case treated with precursor of 1:1, the organic layer was repeatedly washed with deionized water until the aqueous layer became neutral, dried with $\mathrm{MgSO}_{4}$ and filtered.

In the case of 2:1, $n$-hexane $(10 \mathrm{~mL})$ was added, and 
the organic layer was repeatedly washed with deionized water. $n$-Hexane $(50 \mathrm{~mL})$ was added to this solution, and the solution was left standing at $-30^{\circ} \mathrm{C}$ in a refrigerator for a night. The precipitated solid was filtered and dried at reduced pressure. The products were characterized by FT-IR, ${ }^{1} \mathrm{H},{ }^{29} \mathrm{Si}$ NMR, MALDI-TOF MS measurements. When product was pure in spectral analyses, fine crystals suitable for X-ray crystallography were obtained by slow evaporation of a $10 \mathrm{wt} \%$ THF/i-propanol (1:1) solution of the compound. From these procedures, trimethylsilylated T4OTMS (78.3\% yield); "cyclic sym-cis 1,3,5,7-tetrakis(trimethylsilyl)tetraphenyltetrasilsesquioxane", T7OTMS (54.1\%); "3,7,14-tris(trimethylsilyl)heptaphenyltricyclo[7.3.3.1 $1^{5,11}$ ]heptasilsesquioxane", DDT8OTMS (68.2\%); "5,11,14,17-tetrakis(trimethylsilyl)octaphenyltetracyclo[7.3.3.3. $3^{3,7}$ octasilsesquioxane" were obtained.

Additional crystallographic data of T7OTMS (CCDC299793) and DDT8OTMS (CCDC299794) can be obtained free of charge via www.ccdc.cam.au. uk/data-request/cif, by emailing data-request@ccdc. cam.ac.uk.

\section{5,11,14,17-Tetra(hydro)octaphenyltetracyclo[7.3.3.- $3^{3,7}$ Joctasilsesquioxane (DDT8OH)}

Acetic acid $(0.6 \mathrm{~g}, 10 \mathrm{mmol})$ was added dropwise to THF (30 mL) dispersion of double decker tetrasodium salt, 5,11,14,17-tetra(sodio)octaphenyltetracyclo[7.3.$3.3^{3,7}$ ] octasilsesquioxanolate (DDT8ONa, $2.9 \mathrm{~g}, 2.5$ $\mathrm{mmol}$ ), obtained by refluxing for $4 \mathrm{~h}$, and further stirring for $15 \mathrm{~h}$ at room temperature under the standard reaction conditions (phenyltrimethoxysilane, $i$-propanol and $\mathrm{NaOH}$ as monomer, solvent and catalyst; monomer $/ \mathrm{H}_{2} \mathrm{O} /$ catalyst $=1.00 / 1.15 / 0.66$ in molar ratio). Stirring was continued at room temperature for $1 \mathrm{~h}$, and the solution was neutralized with a saturated aqueous sodium hydrogen carbonate $(10 \mathrm{~mL})$, and washed with deionized water $(10 \mathrm{~g})$. The organic layer was dried over anhydrous magnesium sulfate, filtered and evaporated. The solid was again washed with acetonitrile to obtain a colorless product in $50.3 \%$ yield. The compound is soluble in THF, acetone and insoluble in $n$-hexane, methanol, acetonitrile, benzene, toluene, cyclohexane, carbon tetrachloride, dichloromethane, and diethyl ether. $\mathrm{Mp} 230.7^{\circ} \mathrm{C}$, Single crystals suitable for X-ray crystallography were obtained by slow evaporation of a $10 \mathrm{wt} \% \mathrm{THF} /$ $i$-propanol (1:1) solution.

${ }^{1} \mathrm{H}$ NMR $\left(500 \mathrm{MHz}, \mathrm{CDCl}_{3}\right) \delta 2.82(4 \mathrm{H}, \mathrm{s},-\mathrm{OH})$, $2.79(4 \mathrm{H}, \mathrm{s},-\mathrm{OH}), 7.23(8 \mathrm{H}, \mathrm{t}, J=7.5 \mathrm{~Hz}, m-\mathrm{Ph}-H)$, $7.28(8 \mathrm{H}, \mathrm{t}, J=7.5 \mathrm{~Hz}, m-\mathrm{Ph}-H), 7.38(4 \mathrm{H}, \mathrm{t}, J=$ $7.5 \mathrm{Hzz}, p$ - $\mathrm{Ph}-H), 7.43(4 \mathrm{H}, \mathrm{t}, J=7.5 \mathrm{~Hz}, p-\mathrm{Ph}-H)$, $7.47(8 \mathrm{H}, \mathrm{d}, o-\mathrm{Ph}-H), 7.63(8 \mathrm{H}, \mathrm{d}, o-\mathrm{Ph}-H) .{ }^{29} \mathrm{Si}\left\{{ }^{1} \mathrm{H}\right\}$ NMR (THF and $\mathrm{CDCl}_{3}$, TMS) $\delta-69.45(\mathrm{OSiPhOH})$; $-79.62\left(\mathrm{O}_{3} \mathrm{SiPh}\right) . \quad \mathrm{IR}(\mathrm{KBr}): 1431,1595(\mathrm{Si}-\mathrm{Ph})$,
1200-950 (Si-O-Si), 3280 (br, Si-OH) cm ${ }^{-1}$. MALDITOF $(m / z): 1092.32\left([\mathrm{M}+\mathrm{Na}]^{+}\right.$, calc'd: 1091.08). SEC: $M_{\mathrm{n}} 872, M_{\mathrm{w}} 874 M_{\mathrm{w}} / M_{\mathrm{n}} 1.00209$. TGA (ceramic yield $82 \%$ in $\mathrm{N}_{2}$ ).

\section{7,7,17,17-Tetramethyl-1,3,5,9,11,13,15,1-octaphen-} ylhexacyclo[9.13.1 $1^{1,9} \cdot 1^{3,15} \cdot 1^{5,13} \cdot 1^{11,19}$ ]decasiloxane (DDT8ODMS)

Dichlorodimethylsilane $(0.97 \mathrm{~g}, 7.5 \mathrm{mmol})$ was added dropwise to a solution of the tetrasodium salt precursor (DDT8ONa, $2.9 \mathrm{~g}, 2.5 \mathrm{mmol}$ ), triethylamine $(0.75 \mathrm{~g}, 7.5 \mathrm{mmol})$ in toluene $(25 \mathrm{~g})$ for one minute while stirring by a magnetic stirrer under nitrogen. Stirring was further continued at a room temperature for $3 \mathrm{~h}$. Deionized water $(10 \mathrm{~g})$ was added to remove the formed salt, and the reaction product was separated as an organic solution by a separating funnel. The organic layer was repeatedly washed with deionized water until the aqueous layer became neutral, dried with anhydrous magnesium sulfate, filtered and evaporated to obtain $1.4 \mathrm{~g}$ of a white solid. Product is soluble in THF, benzene, dichloromethane, pyridine, acetone, ethyl ether and insoluble in cyclohexane, methanol, $n$-hexane, acetonitrile. mp $272.9^{\circ} \mathrm{C}$, $47.8 \%$ yield.

${ }^{1} \mathrm{H}$ NMR $\left(500 \mathrm{MHz}, \mathrm{CDCl}_{3}\right) \delta 0.311\left(36 \mathrm{H}, \mathrm{s}, \mathrm{CH}_{3}\right)$, $7.19(8 \mathrm{H}, \mathrm{t}, J=7.5 \mathrm{~Hz}, m-\mathrm{Ph}-H), 7.26(8 \mathrm{H}, \mathrm{t}, J=7.5$ $\mathrm{Hz}, m-\mathrm{Ph}-H), 7.34(4 \mathrm{H}, \mathrm{t}, J=7.5 \mathrm{~Hz}, p-\mathrm{Ph}-H), 7.39$ $(4 \mathrm{H}, \mathrm{t}, J=7.5 \mathrm{~Hz}, p-\mathrm{Ph}-H), 7.43(8 \mathrm{H}, \mathrm{d}, J=7.5 \mathrm{~Hz}$, $o$ - $\mathrm{Ph}-H), 7.54(8 \mathrm{H}, \mathrm{d}, J=7.5 \mathrm{~Hz}, o-\mathrm{Ph}-H) .{ }^{29} \mathrm{Si}\left\{{ }^{1} \mathrm{H}\right\}$ NMR $\left(\mathrm{CDCl}_{3}\right.$, TMS $\delta-16.56\left(\mathrm{OSiMe}_{3}\right) ;-78.60$, $-79.59\left(\mathrm{O}_{3} \mathrm{SiPh}\right) . \quad \mathrm{IR}(\mathrm{KBr}): 1431,1594$ ( $\left.\mathrm{Si}-\mathrm{Ph}\right)$, 1200-950 (Si-O-Si), $1263\left(\mathrm{Si}_{-} \mathrm{CH}_{3}\right) \mathrm{cm}^{-1}$. MALDITOF $(m / z): 1203.29\left([\mathrm{M}+\mathrm{Na}]^{+}\right.$, calc ${ }^{\prime} \mathrm{d}:$ 1203.09). SEC: $M_{\mathrm{n}} 879, M_{\mathrm{w}} 880, M_{\mathrm{w}} / M_{\mathrm{n}} 1.00$.

\section{RESULTS AND DISCUSSION}

The synthetic scheme is shown in Scheme 1.

When tri(methoxy)phenylsilane was reacted with water in the presence of sodium hydroxide ( $\mathrm{Si}: \mathrm{Na}$ : $\mathrm{H}_{2} \mathrm{O}=1.0: 1.0: 1.0$ ) in alcohol ( $i$-propanol or $i$-butanol), a distinct product was formed. The product was capped with trimethylchlorosilane, and the solvent was removed with a rotary evaporator. This compound was identified as tetrakis(trimethylsilylated)

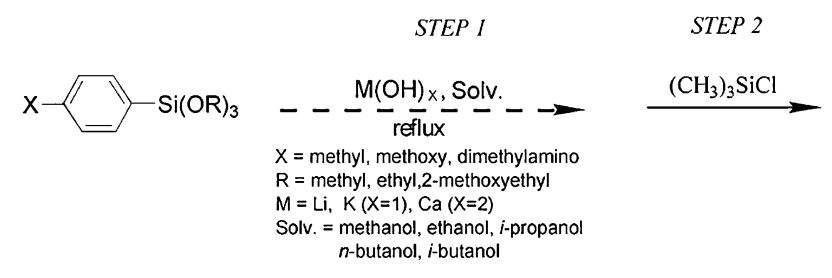

Scheme 1. Reaction of tri(alkoxy)phenylsilane. 


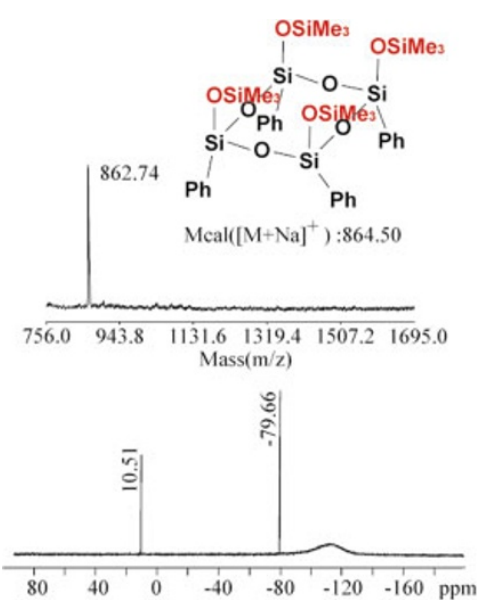

Figure 1. MALDI-TOF MS and ${ }^{29} \mathrm{Si}$ NMR spectra of products obtained under reaction condition; monomer $/ \mathrm{H}_{2} \mathrm{O} / \mathrm{NaOH}=$ $1.00 / 1.00 / 1.00 \mathrm{~mol} / \mathrm{mol} / \mathrm{mol}$, refluxing for $4 \mathrm{~h}$ and stirring for $15 \mathrm{~h}$ at r.t. from trimethoxyphenylsilane.

cyclic sym-cis tetraphenylsilsesquioxane (T4OTMS) as shown in Figure 1. This is an interesting finding similar to Shchegolikhina. ${ }^{17}$

Small amounts of trans and trans-cis isomers were also formed at higher concentration, or under acidic condition at higher reaction temperature. The isomers exist as equilibrium mixture. The reason why only sym-cis isomer was isolated in this report is because of high crystallinity and low solubility of the symcis isomer. The use of other ordinary organic solvents than alcohol did not give any specific product. Substitution of the para position of phenyl group also gave complex product mixture.

To study the reaction process, products obtained in the reactions with $\mathrm{Si}: \mathrm{Na}=2.0: 1.0$ and 1.0:1.0 by refluxing for 1 or $2 \mathrm{~h}$ were analyzed.

MALDI-TOF MS spectra shown in Figure 2 indicated a complex product mixture. We could recognize the formation of cubic T8 in the initial stage of the reaction $(1 \mathrm{~h}, 2 \mathrm{~h})$ when the $\mathrm{Si}$ and $\mathrm{Na}$ was $2: 1$. Although

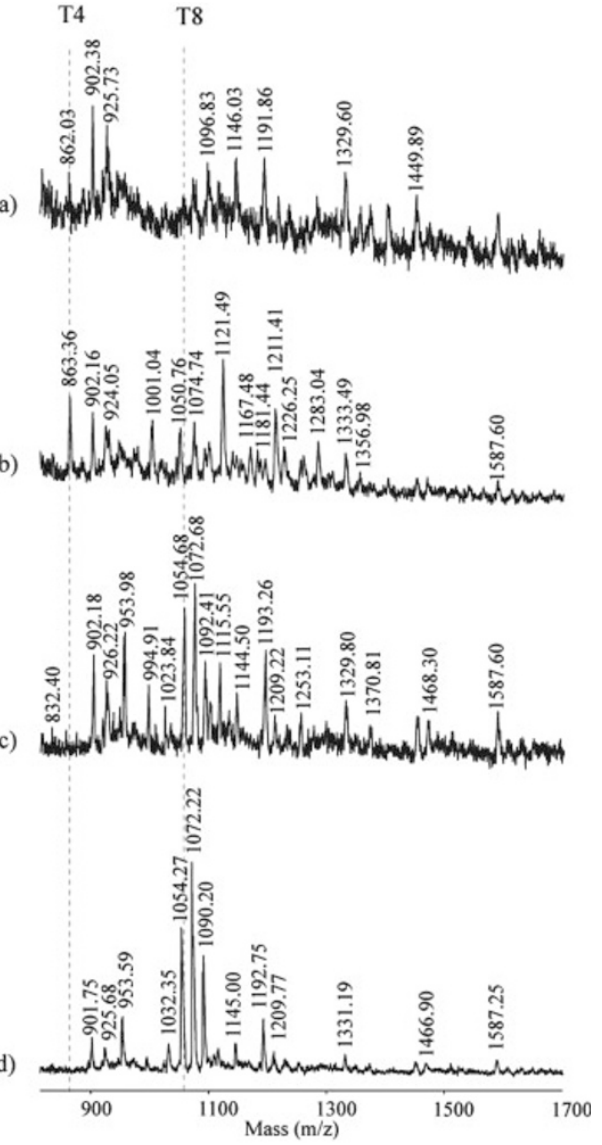

Figure 2. MALDI-TOF MS spectra of products obtained under reaction condition; $\mathrm{Si}: \mathrm{Na}=1: 1(\mathrm{a}, \mathrm{b})$ or $2: 1(\mathrm{c}, \mathrm{d}) \mathrm{mol} / \mathrm{mol}$, refluxing for 1 or $2 \mathrm{~h}$.

T4OTMS was also noticed as a weak peak in $30 \mathrm{~min}$ reaction, it was not possible to conclude the formation of T4OTMS without doubt owing to low signal noise ratio. Contrary, when the ratio was $1: 1$, cubic T8 was not observed even in the initial stage of the reaction. T4OTMS was clearly identified, and its amounts increased with reaction time (final yield, 78.3\%).

More interesting products were identified with longer reaction time in the case of the ratio being $2: 1$.

$\mathrm{PhSi}(\mathrm{OMe})_{3}+\mathrm{H}_{2} \mathrm{O} \stackrel{\mathrm{NaOH}, i \text {-Butanol }}{\longrightarrow}$ refluxing $4 \mathrm{~h}$ and stirring for $15 \mathrm{~h}$ or $40 \mathrm{~h}$ at room temperature

The product formed after $15 \mathrm{~h}$ of stirring was isolated as trimethylsilyl(TMS)-capped compound and purified. The change in TOF-MS and ${ }^{29} \mathrm{Si}$ NMR spectra with stirring time at room temperature are shown in Figure 3.

All spectral data suggested the 3,7,14-tris(trimethylsilyl)heptaphenyltricyclo[7.3.3.1 $1^{5,11}$ ] heptasilsesquioxane (T7OTMS). Molecular mass of $\mathrm{Na}^{+}$-ionized products (1170.75) was close to the calculated value $(1169.18 \mathrm{~m} / z)$ for T7OTMS. ${ }^{29} \mathrm{Si}$ NMR showed three peaks indicating a $\mathrm{T}^{3}$ structure having a phenyl group.
The X-ray single crystal analysis is shown in Figure 4(a) and Tables I, II.

This product was identified as 3,7,14-tris(trimethylsilyl)heptaphenyltricyclo[7.3.3.1 ${ }^{5,11}$ ] heptasilsesquioxane $(54.1 \%$ yield $)$.

After $40 \mathrm{~h}$ stirring, another product with 1379.47 $\mathrm{m} / \mathrm{z}$ (calculated 1379.24) and two ${ }^{29} \mathrm{Si}$ signals at -76.12 and $-78.94\left(\mathrm{O}_{3} \mathrm{SiPh}\right)$ was obtained after trimethylsilylation. The structure of the purified product was also characterized unambiguously by single crystal XRD after recrystallization by slow evaporation of 

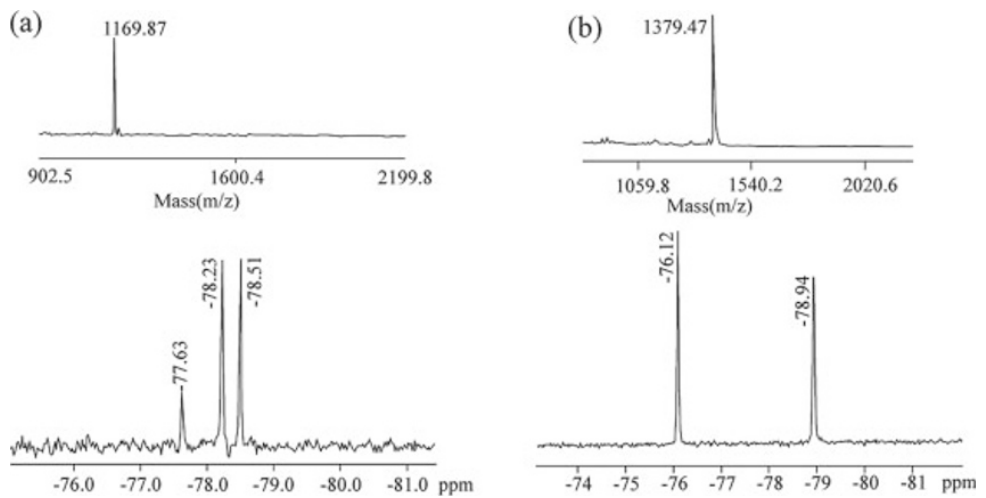

Figure 3. MALDI-TOF MS and ${ }^{29} \mathrm{Si}$ NMR spectra of products obtained from trimethoxyphenylsilane by refluxing for $4 \mathrm{~h}$ and stirring for (a) $15 \mathrm{~h}$, (b) $40 \mathrm{~h}$ at r.t. in $i$-butanol.
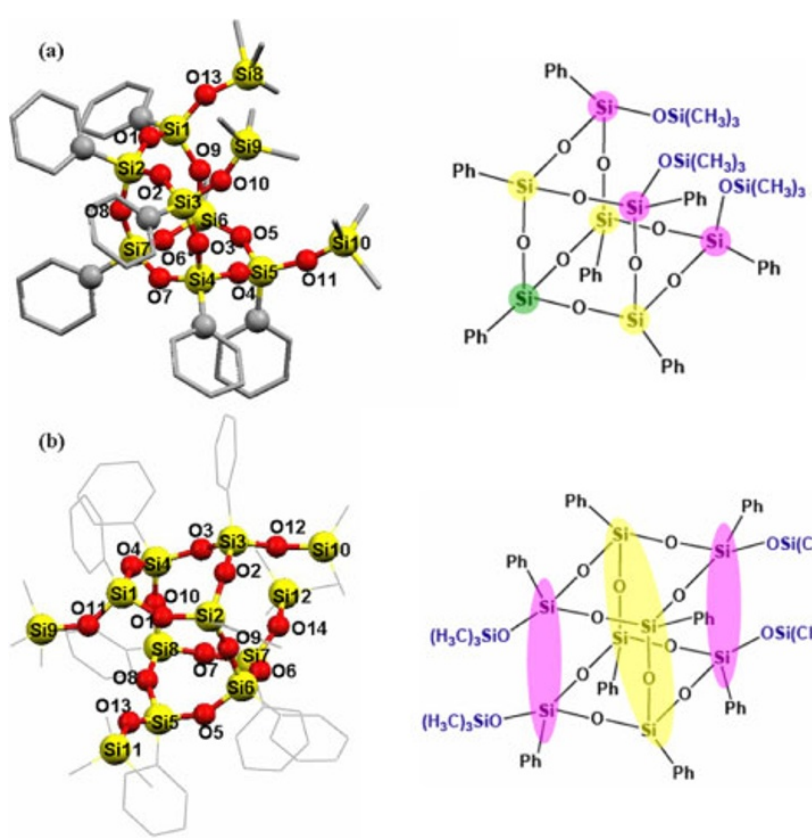

Figure 4. ORTEP plots determined by single-crystal X-ray diffraction for products (a) and (b) in Figure 3.

a $10 \mathrm{wt} \% \mathrm{THF} / i$-propanol (1:1) solution.

ORTEP plots proved the compound as tetrakis(trimethylsilylated) "double-decker" octaphenylsilsesquioxane, 5,11,14,17-tetrakis(trimethylsilyl)tetracyclo$\left[\right.$ 7.3.3.3 $\left.{ }^{3,7}\right]$ octasilsesquioxane (DDT8OTMS, 68.2\% yield), (Figure $4 b$ ).

The bond distances and angles are also collected in Tables I and II together with cubic octaphenylsilsesquioxane (cubic T8) ${ }^{18}$ Silicon-oxygen bond distances $[1.61-1.62 \AA$ except for $\mathrm{Si}(6)-\mathrm{O}(5)]$ and silicon-oxygen-silicon bond angles $\left(\sim 150^{\circ}\right)$ for the cyclic tetrasiloxane structure in upper and lower decks of DDT8OTMS are quite similar with those in cubic $\mathrm{Ph}_{8} \mathrm{Si}_{8} \mathrm{O}_{8}\left(1.61 \AA, 149^{\circ}\right)$. The distances of outer $\mathrm{Si}-\mathrm{O}$ bond were a little shorter $(\sim 1.60 \AA)$. It should be noted that the bond distances between silicon-oxygen bonds in the bridge to connect two decks are also a lit-
Table I. Selected bond distances $(\AA)$ on product from $i$-butanol

\begin{tabular}{|c|c|c|c|}
\hline \multicolumn{4}{|c|}{ Bond distances $(\AA)$} \\
\hline $15 \mathrm{~h}$ & & $40 \mathrm{~h}$ & \\
\hline Si1-O1 & $1.619[16]$ & Si1-O1 & $1.625[1]$ \\
\hline Si1-O9 & $1.583[18]$ & Si1-O4 & $1.617[1]$ \\
\hline Si1-O13 & $1.614[16]$ & Si1-O11 & $1.596[2]$ \\
\hline $\mathrm{Si2}-\mathrm{O} 1$ & $1.608[17]$ & $\mathrm{Si2-O1}$ & $1.607[2]$ \\
\hline $\mathrm{Si} 2-\mathrm{O} 2$ & $1.608[18]$ & $\mathrm{Si} 2-\mathrm{O} 2$ & $1.611[1]$ \\
\hline $\mathrm{Si} 2-\mathrm{O} 8$ & $1.615[16]$ & $\mathrm{Si} 2-\mathrm{O} 9$ & $1.595[1]$ \\
\hline $\mathrm{Si} 3-\mathrm{O} 2$ & $1.621[17]$ & $\mathrm{Si} 3-\mathrm{O} 2$ & $1.608[1]$ \\
\hline $\mathrm{Si3}-\mathrm{O} 3$ & $1.607[16]$ & $\mathrm{Si3}-\mathrm{O} 3$ & $1.618[1]$ \\
\hline $\mathrm{Si3}-\mathrm{O} 10$ & $1.587[19]$ & $\mathrm{Si3-O12}$ & $1.598[2]$ \\
\hline $\mathrm{Si} 4-\mathrm{O} 3$ & $1.609[17]$ & $\mathrm{Si} 4-\mathrm{O} 3$ & $1.608[2]$ \\
\hline $\mathrm{Si} 4-\mathrm{O} 4$ & $1.615[18]$ & $\mathrm{Si} 4-\mathrm{O} 4$ & $1.609[1]$ \\
\hline $\mathrm{Si} 4-\mathrm{O} 7$ & $1.613[17]$ & Si4-O10 & $1.599[1]$ \\
\hline $\mathrm{Si5-O4}$ & $1.607[19]$ & Si5-O5 & $1.613[2]$ \\
\hline $\mathrm{Si5-O5}$ & $1.604[17]$ & Si5-O8 & $1.618[1]$ \\
\hline Si5-O11 & $1.590[2]$ & $\mathrm{Si5-O13}$ & $1.592[1]$ \\
\hline $\mathrm{Si6}-\mathrm{O} 5$ & $1.599[16]$ & Si6-O5 & $1.595[2]$ \\
\hline Si6-O6 & $1.625[16]$ & Si6-O6 & $1.604[1]$ \\
\hline Si6-O13 & $1.605[16]$ & Si6-O9 & $1.597[1]$ \\
\hline $\mathrm{Si7}-\mathrm{O} 6$ & $1.619[16]$ & Si7-O6 & $1.621[1]$ \\
\hline $\mathrm{Si7}-\mathrm{O} 7$ & $1.609[16]$ & Si7-O7 & $1.617[2]$ \\
\hline \multirow[t]{4}{*}{$\mathrm{Si7}-\mathrm{O} 8$} & $1.617[16]$ & $\mathrm{Si7-O14}$ & $1.601[2]$ \\
\hline & & Si8-O7 & $1.597[2]$ \\
\hline & & $\mathrm{Si} 8-\mathrm{O} 8$ & $1.608[1]$ \\
\hline & & Si8-O10 & $1.594[1]$ \\
\hline \multicolumn{4}{|c|}{$\mathrm{Ph}_{8} \mathrm{Si}_{8} \mathrm{O}_{12}{ }^{18}$} \\
\hline $\mathrm{Si} \quad \mathrm{O}$ & 1.614 & & \\
\hline
\end{tabular}

Values in the square bracket indicating the range of error. [1] indicates $\pm 0.001 \AA$.

tle shorter than those in the decks $(\sim 1.60 \AA)$. Interstingly, the bond angles (168.8 and $\left.172.5^{\circ}\right)$ of the bridge $\left(\mathrm{Si}_{2}-\mathrm{O}_{9}-\mathrm{Si}_{6}\right.$ and $\left.\mathrm{Si}_{4}-\mathrm{O}_{10}-\mathrm{Si}_{8}\right)$ were considerably expended, and bigger than those in the deck or cubic structure.

Yoshida's product was not completely consistent with the proposed double decker structure. It was confirmed that their error in NMR spectra was generated 
Table II. Selected bond angles $\left(^{\circ}\right)$ on product from $i$-butanol

\begin{tabular}{|c|c|c|c|}
\hline \multicolumn{4}{|c|}{ Bond angles $\left({ }^{\circ}\right)$} \\
\hline $15 \mathrm{~h}$ & & $40 \mathrm{~h}$ & \\
\hline $\mathrm{O}-\mathrm{Si}-\mathrm{O}$ & & $\mathrm{O}-\mathrm{Si}-\mathrm{O}$ & \\
\hline O1-Si1-O9 & $108.44[10]$ & O4-Si1-O1 & $109.58[8]$ \\
\hline O1-Si1-O13 & $108.40[8]$ & O11-Si1-O4 & $110.79[8]$ \\
\hline O9-Si1-O13 & $109.83[9]$ & O11-Si1-O1 & $107.38[7]$ \\
\hline $\mathrm{O} 1-\mathrm{Si} 2-\mathrm{O} 2$ & $108.81[9]$ & $\mathrm{O} 2-\mathrm{Si} 2-\mathrm{O} 1$ & $108.63[8]$ \\
\hline $\mathrm{O} 1-\mathrm{Si} 2-\mathrm{O} 8$ & $108.31[8]$ & $\mathrm{O} 9-\mathrm{Si} 2-\mathrm{O} 2$ & $107.68[8]$ \\
\hline $\mathrm{O} 2-\mathrm{Si} 2-\mathrm{O} 8$ & $109.59[8]$ & O9-Si2-O1 & $110.60[8]$ \\
\hline $\mathrm{O} 2-\mathrm{Si} 3-\mathrm{O} 3$ & $109.42[8]$ & $\mathrm{O} 3-\mathrm{Si3}-\mathrm{O} 2$ & $109.33[8]$ \\
\hline O2-Si3-O10 & $108.24[9]$ & O12-Si3-O3 & $106.77[7]$ \\
\hline O3-Si3-O10 & $109.20[10]$ & $\mathrm{O} 12-\mathrm{Si} 3-\mathrm{O} 2$ & $110.92[8]$ \\
\hline O3-Si4-O4 & $109.02[9]$ & O4-Si4-O3 & $109.63[7]$ \\
\hline O3-Si4-O7 & $110.07[9]$ & O10-Si4-O3 & $110.22[8]$ \\
\hline O4-Si4-O7 & $109.32[8]$ & O10-Si4-O4 & $108.35[8]$ \\
\hline O4-Si5-O5 & $109.58[9]$ & O8-Si5-O5 & $109.05[8]$ \\
\hline O4-Si5-O11 & $108.57[10]$ & O13-Si5-O8 & $107.98[7]$ \\
\hline O5-Si5-O11 & $108.46[9]$ & O13-Si5-O5 & $110.39[7]$ \\
\hline O5-Si6-O6 & $108.81[8]$ & O6-Si6-O5 & $109.96[8]$ \\
\hline O5-Si6-O13 & $108.43[8]$ & O9-Si6-O5 & $108.87[9]$ \\
\hline O6-Si6-O13 & $110.01[8]$ & O9-Si6-O6 & $108.47[8]$ \\
\hline O6-Si7-O7 & $109.75[8]$ & O7-Si7-O6 & $109.07[8]$ \\
\hline O6-Si7-O8 & $108.01[8]$ & O14-Si7-O6 & $107.78[8]$ \\
\hline O7-Si7-O8 & $110.61[8]$ & O14-Si7-O7 & $111.20[8]$ \\
\hline $\mathrm{Si}-\mathrm{O}-\mathrm{Si}$ & & O8-Si8-O7 & $109.43[7]$ \\
\hline Si1-O1-Si2 & $147.89[11]$ & O10-Si8-O8 & $108.93[7]$ \\
\hline $\mathrm{Si} 2-\mathrm{O} 2-\mathrm{Si} 3$ & $149.54[12]$ & O10-Si8-O7 & $109.43[8]$ \\
\hline $\mathrm{Si3}-\mathrm{O} 3-\mathrm{Si} 4$ & $148.81[11]$ & $\mathrm{Si}-\mathrm{O}-\mathrm{Si}$ & \\
\hline Si4-O4-Si5 & $151.65[11]$ & Si1-O1-Si2 & $145.3[1]$ \\
\hline Si5-O5-Si6 & $160.11[11]$ & $\mathrm{Si} 2-\mathrm{O} 2-\mathrm{Si} 3$ & $148.67[9]$ \\
\hline Si6-O6-Si7 & $142.59[10]$ & $\mathrm{Si} 3-\mathrm{O} 3-\mathrm{Si} 4$ & $143.71[9]$ \\
\hline Si4-O7-Si7 & $152.15[10]$ & $\mathrm{Si1}-\mathrm{O} 4-\mathrm{Si} 4$ & $147.43[9]$ \\
\hline Si2-O8-Si7 & $148.47[10]$ & $\mathrm{Si} 5-\mathrm{O} 5-\mathrm{Si} 6$ & $148.9[1]$ \\
\hline \multirow[t]{5}{*}{ Si1-O9-Si6 } & $159.52[12]$ & Si6-O6-Si7 & $146.3[1]$ \\
\hline & & $\mathrm{Si7-O7-Si8}$ & $156.14[8]$ \\
\hline & & $\mathrm{Si} 5-\mathrm{O} 8-\mathrm{Si} 8$ & $148.8[1]$ \\
\hline & & $\mathrm{Si} 2-\mathrm{O} 9-\mathrm{Si} 6$ & $168.8[1]$ \\
\hline & & Si4-O10-Si8 & $172.5[1]$ \\
\hline \multicolumn{4}{|l|}{$\mathrm{Ph}_{8} \mathrm{Si}_{8} \mathrm{O}_{12}{ }^{18}$} \\
\hline O-Si-O & & $\mathrm{Si}-\mathrm{O}-\mathrm{Si}$ & \\
\hline $\mathrm{O} \quad \mathrm{Si} \quad \mathrm{O}$ & 109.0 & $\begin{array}{lll}\mathrm{Si} & \mathrm{O} & \mathrm{Si}\end{array}$ & 149.2 \\
\hline
\end{tabular}

Values in the square bracket indicating the range of error. [8] indicates $\pm 0.08^{\circ}$.

by the existence of $\mathrm{T} 7$ as a by-product as evidenced by MALDI-TOF MS spectroscopy (Figure 5).

Conversion of $\mathrm{T} 7$ to double decker structure was more clearly seen when phenyltriethoxysilane was used instead of phenyltrimethoxysilane (Figure 6).

The only product after $15 \mathrm{~h}$ was the T7, which was slowly converted into the DDT8 after $70 \mathrm{~h}$. Both compounds were present as the major products after $40 \mathrm{~h}$ standing. These results strongly supported that the DDT8 was produced with the consumption of T7, different from the case of cubic T8 formation. The possibility for sym-cis cyclic tetramer being an intermedi-

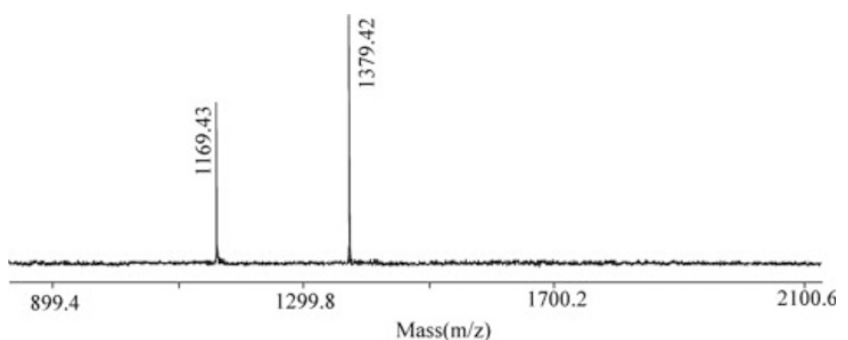

Figure 5. MALDI-TOF MS spectrum of DDT8OTMS synthesized by reported method. ${ }^{16}$

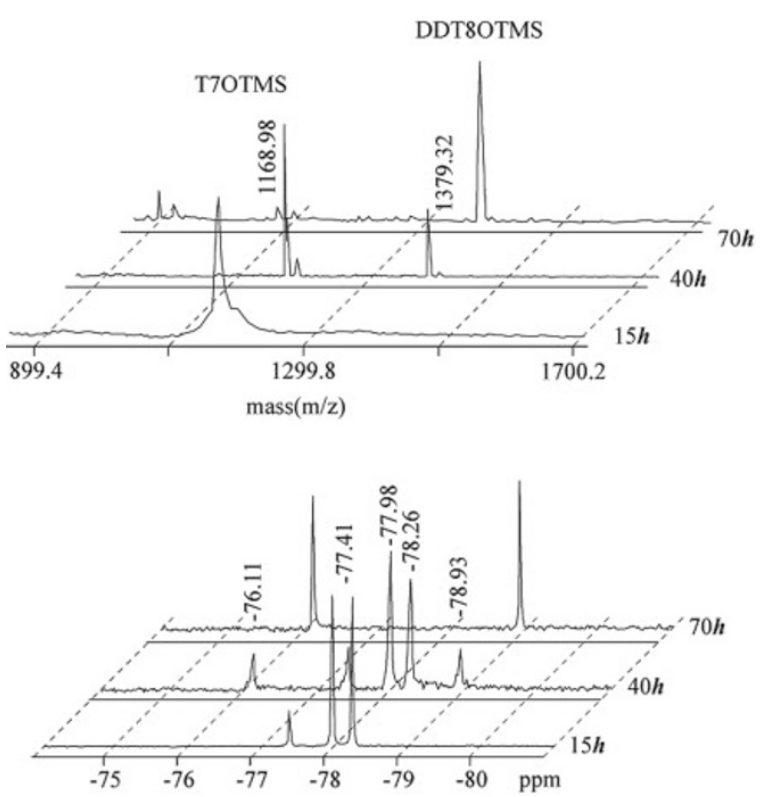

Figure 6. MALDI-TOF MS and ${ }^{29} \mathrm{Si}$ NMR spectra of products obtained from triethoxyphenylsilane in $i$-propanol by refluxing for $4 \mathrm{~h}$ and stirring for 15,40 , and $70 \mathrm{~h}$ at r.t.

ate to $\mathrm{T} 7$ and DDT8 or cubic $\mathrm{T} 8$ will be clarified in future report.

To find effective reaction conditions for the formation of substituted DDT8 structures, the standard reaction conditions were modified. The effects of substituent at para position [hydrogen $(*)$, methyl(a), methoxy(b), dimethylamino(c)], alkoxy group [methoxy $(*)$, ethoxy(d), 2-methoxyethoxy(e)], solvent $[i-$ propanol $(*)$, methanol(f), ethanol(g), $n$-butanol(h), $i$ butanol(i)] and catalyst $[\mathrm{NaOH}(*), \mathrm{LiOH}(\mathrm{j}), \mathrm{KOH}(\mathrm{k})$, $\left.\mathrm{Ca}(\mathrm{OH})_{2}(\mathrm{l})\right]$ were studied. Products could not be isolated because of the solubility problems of the crude products in a, f, g, h, $\mathrm{k}$ (products were soluble in $i$ propanol), nor in e, $\mathrm{j}$ (products could not be recrystallized). Reaction conditions b, c, d, and i gave some products. The products obtained from $b, c$ were a mixture compound, which could not be characterized. Pure T7 was obtained in reaction condition $(\mathrm{d}, \mathrm{i})$ like above results.

Double-decker 5,11,14,17-tetra(hydro)octaphenyltetracyclo[7.3.3.3 $\left.3^{3,7}\right]$ octasilsesquioxane (DDT8OH) 
was obtained from DDT8ONa by neutralization with acetic acid, which was also characterized by MALDITOF MS, NMR and single crystal XRD analyses after re-precipitation and washing with acetonitrile. MALDI-TOF $\left([\mathrm{M}+\mathrm{Na}]^{+}, 1092.32 \mathrm{~m} / z\right.$; calculated 1091.08) and ${ }^{29} \mathrm{Si}$ NMR $(-69.45,-79.62)$ (Figure 7) supported the double decker structure.

ORTEP plots of DDT8OH determined by XRD analysis are shown in Figure 8(a). Crystal of DDT8OH included two THF molecules in the crystal.

In Figure 8(b), it was shown that the oxygen-oxygen distances in a deck of DDT8OH were averagely 3.62 and $3.71 \AA\left(\mathrm{O}_{1}-\mathrm{O}_{3}\right.$ and $\left.\mathrm{O}_{2}-\mathrm{O}_{4}\right)$, and silicon-silicon distances were 4.16 and $4.29 \mathrm{~A}\left(\mathrm{Si}_{1}-\mathrm{Si}_{3}\right.$ and $\mathrm{Si}_{2}$ $\left.\mathrm{Si}_{4}\right)$, respectively. The distance between terminal oxygen to facing terminal silane (3.966 and $4.566 \AA$ ) was much longer than ordinary Si-O bond (1.609 $\AA$ ). Selected bond distances and angles were collected in Table III. XRD results of DDT8OH were almost the same to those of DDT8OTMS.

The tetrasiloxane rings in T7 and DDT8 structures have sym-cis stereochemistry without trans. One possible mechanism is that $\mathrm{T} 7$ was formed by condensation of all cis T4 with lower linear siloxane or three molecules of phenyltrialkoxysilane itself, and then

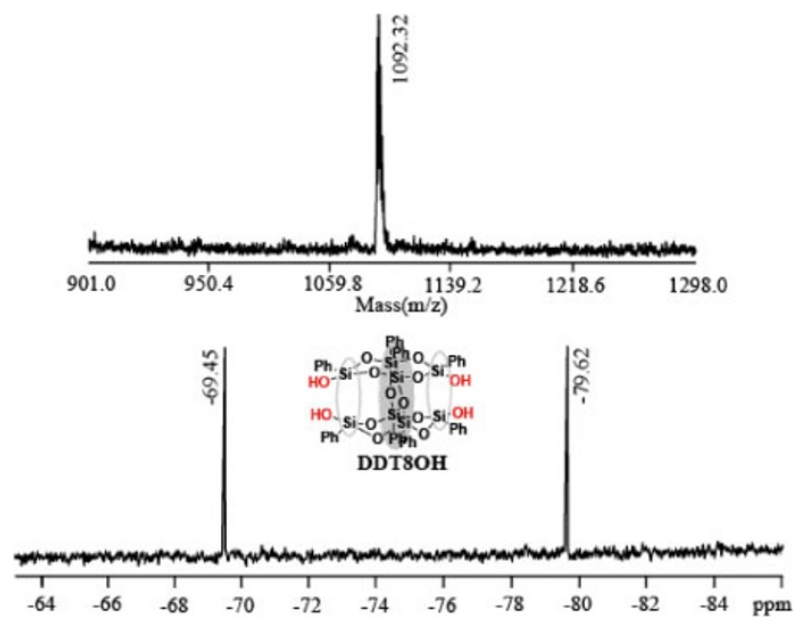

Figure 7. MALDI-TOF MS and ${ }^{29} \mathrm{Si} N \mathrm{NR}$ spectra of and DDT8OH. transformed into double decker T8 by the condensation with a phenyltrialkoxysilane, but the mechanism is not clear at present.

${ }^{29} \mathrm{Si} \mathrm{NMR}$ of DDT8OH clearly showed that $\mathrm{T}_{1}$ of silicon atom in the bridge $\left(\mathrm{O}_{3} \mathrm{SiPh}\right)$ is longer than those of silicon atoms in cubic T8, or silicon atoms of silanol of DDT8OH (OSiPhOH) (Table IV). The silanol silicon stoms showed the shortest $\mathrm{T}_{1}$. By considering the expanded $\mathrm{Si}-\mathrm{O}-\mathrm{Si}$ bonds of the bridge connecting the two tetrasiloxane decks, it may be reasonable to assume that silicon atoms in the bridge have the lowest mobility among the silicon atoms in the double decker, or the cubic structures.

Thermal properties of DDT8OH were compared with DDT8OTMS under nitrogen atmosphere to ex-

Table III. Selected bond distances $(\AA)$ and bond angles $\left({ }^{\circ}\right)$ for DDT8OH

\begin{tabular}{|c|c|c|c|}
\hline \multicolumn{4}{|c|}{ Bond distances $(\AA)$} \\
\hline Si1-O1 & $1.616(2)$ & $\mathrm{Si} 3-\mathrm{O} 2$ & $1.613(1)$ \\
\hline Si1-O4 & $1.617(1)$ & $\mathrm{Si} 3-\mathrm{O} 3$ & $1.617(2)$ \\
\hline $\mathrm{Si} 1-\mathrm{O} 5$ & $1.609(2)$ & $\mathrm{Si} 3-\mathrm{O} 7$ & $1.584(2)$ \\
\hline $\mathrm{Si} 2-\mathrm{O} 1$ & $1.600(2)$ & $\mathrm{Si} 4-\mathrm{O} 3$ & $1.602(2)$ \\
\hline $\mathrm{Si} 2-\mathrm{O} 2$ & $1.600(1)$ & $\mathrm{Si} 4-\mathrm{O} 4$ & $1.603(2)$ \\
\hline $\mathrm{Si} 2-\mathrm{O} 6$ & $1.594(2)$ & & \\
\hline \multicolumn{4}{|c|}{ Bond angles $\left({ }^{\circ}\right)$} \\
\hline \multicolumn{4}{|l|}{ O-Si-O } \\
\hline O4-Si1-O1 & 110.64(9) & O7-Si3-O3 & 111.1(1) \\
\hline O5-Si1-O1 & $105.2(1)$ & O4-Si4-O3 & $110.9(1)$ \\
\hline O5-Si1-O4 & $110.3(1)$ & & \\
\hline $\mathrm{O} 2-\mathrm{Si} 2-\mathrm{O} 1$ & $109.18(8)$ & $\mathrm{Si}-\mathrm{O}-\mathrm{Si}$ & \\
\hline O6-Si2-O1 & $108.58(9)$ & Si1-O1-Si2 & $150.36(9)$ \\
\hline $\mathrm{O} 6-\mathrm{Si} 2-\mathrm{O} 2$ & 109.2(1) & $\mathrm{Si} 2-\mathrm{O} 2-\mathrm{Si} 3$ & $165.6(1)$ \\
\hline $\mathrm{O} 3-\mathrm{Si3}-\mathrm{O} 2$ & $108.4(1)$ & $\mathrm{Si3}-\mathrm{O} 3-\mathrm{Si} 4$ & $145.4(2)$ \\
\hline $\mathrm{O} 7-\mathrm{Si} 3-\mathrm{O} 2$ & $109.4(1)$ & Si1-O4-Si4 & $148.3(1)$ \\
\hline
\end{tabular}

Table IV. ${ }^{29} \mathrm{Si}$ spin-lattice relaxation times in the laboratory frame $\mathrm{T}_{1}(\mathrm{Si})(\mathrm{ms})$, chemical shifts $\delta(\mathrm{ppm})$

\begin{tabular}{llc}
\hline \multirow{2}{*}{ Silicon atom } & \multicolumn{2}{c}{${ }^{29} \mathrm{Si}$ spin-lattice relaxation time $\left(\mathrm{T}_{1}, \mathrm{~ms}\right)$} \\
\cline { 2 - 3 } & $\mathrm{DDT} 8 \mathrm{OH}$ & Cubic type \\
\hline $\mathrm{OSi} \mathrm{PhOH}$ & $94.5(-70.39)$ & \\
$\mathrm{O}_{3} \mathrm{SiPh}$ & $119(-78.74)$ & $112(-77.99)$ \\
\hline
\end{tabular}

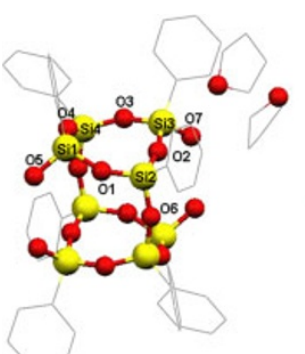

(a)

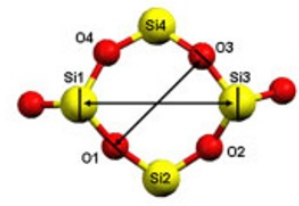

(b)

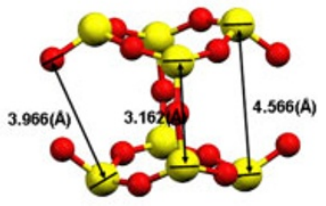

(c)

Figure 8. ORTEP plot(a) of DDT8OH determined by XRD, (a) all view, (b) top view (c) side view. 


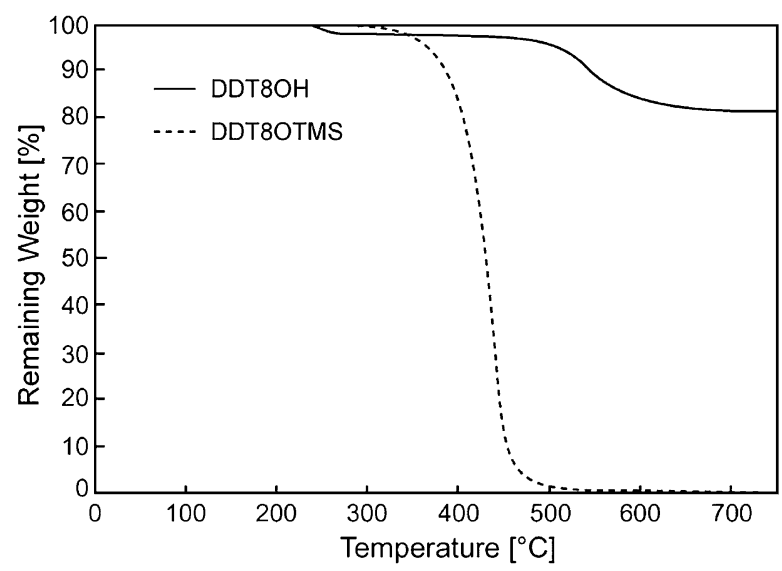

Figure 9. TGA curves for DDT8OH and DDT8OTMS.

Table V. Decomposition temperature $\left(T_{\mathrm{dec}}\right)$ and ceramic yield (\%) of DDT8OTMS and DDT8OH obtained by TGA

\begin{tabular}{ccc}
\hline Products & $\begin{array}{c}\text { Decomposition temperature } \\
T_{\mathrm{dec}}\left({ }^{\circ} \mathrm{C}\right) \text { [onset] }\end{array}$ & $\begin{array}{c}\text { Ceramic yield } \\
(\%)\end{array}$ \\
\hline DDT8OTMS & $400^{\mathrm{a}}$ & 0.9 \\
DDT8OH & 505 & 81.5 \\
\hline
\end{tabular}

a: sublimed.

amine the reactivity of the compounds (Figure 9).

The samples (about $11 \mathrm{mg}$ ) were heated from $50^{\circ} \mathrm{C}$ to $800^{\circ} \mathrm{C}$ at the heating rate of $10^{\circ} \mathrm{C} / \mathrm{min}$. DDT8OTMS completely lost its weight between $397-495^{\circ} \mathrm{C}$. Sublimation of the compound was likely. On the other hand, DDT8OH lost less than $2.6 \mathrm{wt} \%$ between $240-500^{\circ} \mathrm{C}$, presumably due to the desorption of adsorbed or condensed water. Decomposition onset began at $505{ }^{\circ} \mathrm{C}$, and the residue yield was $81.5 \%$. Apparently, reactivity of silanol groups in thermal condensation was very low at low temperature. The results are summarized in Table V.

Thermal condensation of DDT8OH was traced by checking the products from 50 to $300^{\circ} \mathrm{C}$ at a heating rate of $10^{\circ} \mathrm{C} / \mathrm{min}$ under $\mathrm{N}_{2}$ by SEC. The SEC showed broad distribution $\left(M_{\mathrm{n}} 4700, M_{\mathrm{w}} 25400, M_{\mathrm{w}} / M_{\mathrm{n}} 5.0\right.$, polystyrene standard) for the products produced at $300^{\circ} \mathrm{C}$. Tetrafunctional silanols in the double decker DDT8OH seem to condense intermolecularly at higher temperature to give polymeric materials. This may be understood by the long distance between terminal silanol oxygen and facing terminal silicon atom of the counter silanol and long spin-lattice relaxation time of the silicon atoms of the bridge. It seems difficult for the terminal silanol oxygen to attack the facing terminal silicon atom to cause intramolecular condensation due to long distance in molecular structure and low mobility in the solid state.

Intramolecular bridging reactivity of DDT8ONa via dimethyl silylation is quite interesting.

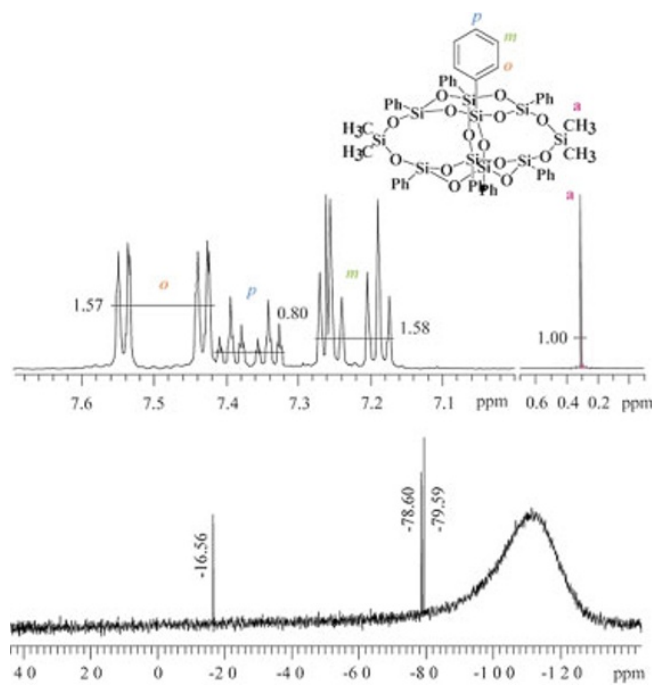

Figure 10. ${ }^{1} \mathrm{H}$ and ${ }^{29} \mathrm{Si} \mathrm{NMR}$ of DDT8ODMS obtained by bridging of DDT8ONa with dimethyldichlorosilane.

Reaction of DDT8ONa with dimethyldichlorosilane gave completely condensed cage, 7,7,17,17-tetramethyl-1,3,5,9,11,13,15,19-octaphenylhexacyclo[9.13.1 ${ }^{1,9}$.$1^{3,15} \cdot 1^{5,13} \cdot 1^{11,19}$ ]decasiloxane (DDT8ODMS) in almost quantitative yield, whose spectra were given in Figure 10. Such high and selective reactivity of facing silanols in the double decker structure will open the possibility to selectively synthesize unique structures of new polysiloxanes.

\section{CONCLUSION}

Tetraphenylsilsesquioxanetetraol (T4), heptaphenylsilsesquioxanetriol (T7) and double-decker octaphenylsilsesquioxanetetraol (DDT8) were obtained from phenyl(m)ethoxysilane in alkaline equilibration reactions. The double-decker T8 seems to be produced with the consumption of $\mathrm{T} 7$ and $\mathrm{T} 4$ in the same condition.

Fine single crystals of trimethylsilylated heptaphenylsilsesquioxane (T7OTMS) and double-decker octaphenylsilsesquioxane (DDT8OTMS) were obtained by slow evaporation of a THF/i-propanol (1:1). Their unambiguous 3D structures were established by single crystal X-ray diffraction analysis.

Pure double decker tetra(hydro)octapheylsilsesquioxane (DDT8OH) was prepared by neutralization of double decker octaphenylsilsesquioxanetetraol tetrasodium salt (DDT8ONa). The tetrasilanol was reluctant to inter or intra molecular condensation till $\sim 230^{\circ} \mathrm{C}$, but was effectively bridged by dimethyldichlorosilane.

Acknowledgment. This work was partly supported by a Grant-in-Aid for Scientific Research from Japan Society for Promotion of Science (16205016), and by 
a Grant-in-Aid for Scientific Research in a Priority Area "Super-Hierarchical Structures" from the Ministry of Education, Culture, Sports, Science and Technology, Japan (18039012).

\section{REFERENCES}

1. M. G. Voronkov and V. L. In, in "Inorganic Ring Systems," Topics in Current Chemistry 102, Springer-Verlag, 1982, p. 199.

2. A. Provatas and J. G. Matisons, Trends Polym. Sci., 5, 327 (1997).

3. R. H. Baney, M. Itoh, A. Sakakibara, and T. Suzuki, Chem. Rev., 95, 1409 (1995).

4. T. S. Haddad and J. D. Lichtenhan, Macromolecules, 29, 7302 (1996).

5. J.-C. Huang, C.-B. He, Y. Xiao, K. Y. Mya, J. Dai, and Y. P. Siow, Polymer, 44, 4491 (2003).

6. S. A. Pellice, D. P. Fasce, and R. J. J. Williams, J. Polym. Sci., Part B: Polym. Phys., 41, 1451 (2003).

7. H. Xu, S.-W. Kuo, J.-S. Lee, and F.-C. Chang, Macro- molecules, 35, 8788 (2002).

8. D. W. Scott, J. Am. Chem. Soc., 68, 356 (1946).

9. A. J. Barry, W. H. Daud, J. J. Domicone, and J. W. Gilkey, J. Am. Chem. Soc., 77, 4248 (1955).

10. J. F. Brown and L. H. Vogt, J. Am. Chem. Soc., 87, 4313 (1965).

11. F. J. Feher and T. A. Budzichowki, Organometallics, 10, 2526 (1991).

12. W. J. Rob, M. Hanssen, A. S. Rutger, and C. L. Hendrikus, Eur. J. Inorg. Chem., 675 (2004).

13. C. Pakjamsai and Y. Kawakami, Polym. J., 36, 455 (2004).

14. C. Pakjamsai, N. Kobayashi, M. Koyano, S. Sasaki, and Y. Kawakami, J. Polym. Sci., Part A: Polym. Chem., 42, 4587 (2004).

15. G. A. Burkhard, J. Org. Chem., 81, 2359 (1950).

16. K. Yoshida, K. Ito, H. Oikawa, M. Yamahiro, Y. Morimoto, K. Ohguma, K. Watanabe, and N. Ootake, United States Patent Application, 20040068074 (2004).

17. O. Shchegolikhina, Y. Pozdniakova, and M. Antipin, Organometallics, 19, 1077 (2000).

18. T. Lin, C. He, and Y. Xiao, J. Phys. Chem. B, 107, 13788 (2003). 